\title{
PACKAGE LEVEL INTEGRATION OF SILICON MICROFABRICATED REACTORS TO FORM A MINIATURE REACTOR TEST SYSTEM
}

\author{
David J. Quiram ${ }^{*}$, Klavs F. Jensen ${ }^{*}$, and Martin A. Schmidt ${ }^{\dagger}$ \\ 'Dept. of Chemical Engineering, ${ }^{\dagger}$ Dept. of Electrical Engineering and Computer Science \\ Massachusetts Institute of Technology \\ Cambridge, MA 02139
}

\author{
James F. Ryley, Patrick L. Mills, Mark D. Wetzel, \\ James W. Ashmead, Richard D. Bryson, \\ Daniel J. Kraus, and Alan P. Stamford \\ DuPont Central Research and Development \\ Wilmington, DE 19880-0357
}

\begin{abstract}
A method for packaging microfabricated reactors is described that allows for the creation of parallel arrays of operating devices for scale-up purposes. As a packaging demonstration, these microreactors are being coupled with microvalves and MEMS mass flow controllers to form a miniature microreactor test station. A novel method based on Known Good Die technology is used for the electrical and fluidic interfaces to the microreactors. The microfluidic components are mounted on standard circuit boards that have the monitoring and control circuitry along with fluidic connections. The boards are housed in a standard 6U CompactPCI chassis utilizing its backplane for the electrical connections between boards. This system will be the first demonstration of a scalable, parallel microreactor array that integrates reactors with other microfluidic devices and the electronic circuitry needed for monitoring and control.
\end{abstract}

\section{INTRODUCTION}

The use of microfabrication techniques to produce microreactors and other miniaturized devices for chemical processing is completing its first decade of active research $[1,2]$. Since the establishment of an annual international conference in the field in 1997, there has been an explosive growth in progress[3-6]. As in any MEMS device, the reasons for miniaturization have to be strong to compete with conventional technologies. There is now overwhelming evidence that miniaturization offers advantages ranging from greater selectivity and conversion to the processing of new materials that could not otherwise be made[6]. A new challenge is to utilize the benefits of microreactor technology for commercial processes. In some cases, a single high throughput device may be adequate, but scale-up is generally needed to increase production rates.

The scale-up of microreactors differs from the traditional scale-up paradigm in that production capacity is increased by creating an array of microreactors running in parallel versus building a larger scale unit $[1,7]$. Although obtaining greater production rates appears to be simpler, this parallelization presents new challenges that have not been addressed in previous efforts[8]. Particularly, the areas of reactor monitoring and control quickly become complex as the system size is increased to massively parallel arrays. More attention has to be placed on the microreactor packaging since both fluidic and electrical interconnections must be designed to allow for parallelization. Questions also arise as to how such systems will perform as a

\author{
Steven J. Medwin and Russell E. Mitchell \\ ENSER Corporation \\ Cinnaminson, NJ 08077
}

whole, and whether they can be designed in such a way to be financially competitive with conventional technology. Efforts in this joint MIT-DuPont program concentrate on developing a technological base for integrating microfabricated chemical reactors into large parallel arrays suitable for on-site production of small quantities of hazardous or thermally unstable chemicals, such as organic peroxides, hydrogen cyanide, organic acids, and related species. With the design and construction of prototype multiple reactor systems, a knowledge base will be created that will eventually lead to commercially viable systems.

\section{BACKGROUND}

The goal of the MIT-DuPont program is to build a prototype microreactor system that incorporates MEMS reactors along with other microfluidic devices. This system will be functionally equivalent to an industrial catalyst test station constructed using conventional technology. Figure 1 shows the layout of a typical system, which is comprised of fluidic components to form a feed gas manifold, a reactor manifold, and a product analysis system. These sections are constructed using valves, pressure regulators, reactors, and mass flow controllers. The microreactor system will be constructed entirely from MEMS devices and will include the feed gas manifold and the reactor manifold. Product analysis will be done using standard technology so the performance of this system can be directly compared to its larger counterpart.

The system being developed utilizes the thin-film, gas-phase microreactor design that originated at MIT at the beginning of this research program $[9,10]$. This device has a single channel with

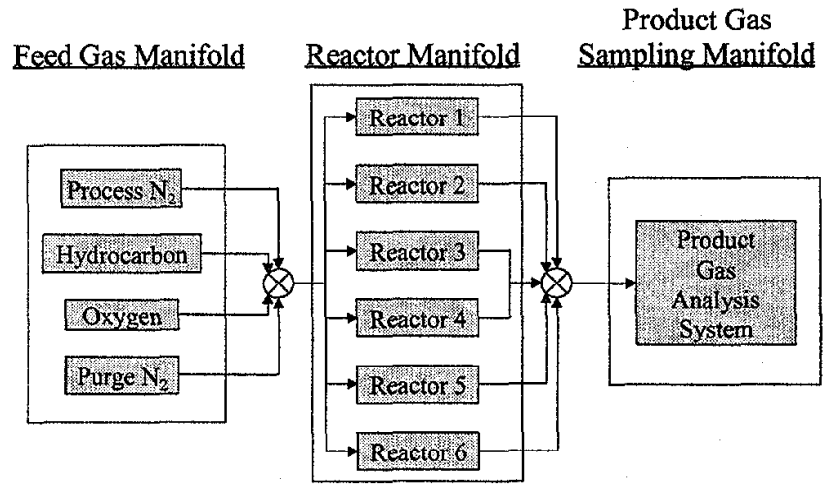

Figure 1. Catalyst test station layout. 
integrated heating and temperature sensing. Figure 2 shows the top and cross-sectional views of the reactor, which has a reactant inlet and product outlet on opposite ends of the channel. The bottom of the channel is sealed by a Pyrex layer that is anodically bonded to the silicon die. The Pyrex has drilled holes for the gas inlet and outlets. This reactor differs from the original "T" microreactor in that reactant mixing takes place off-chip in the gas feed manifold. This was done to 1) improve membrane stability; 2) allow direct sampling of the reactant mixture into the product analysis system; and 3) to reduce the overall reactor size. The reaction channel is $0.5 \mathrm{~mm}$ wide, $0.5 \mathrm{~mm}$ deep, and $11 \mathrm{~mm}$ long. It has seven distinct zones for heating and temperature sensing. Each heater is $0.94 \mathrm{~mm}$ in length and the temperature sensors are $0.77 \mathrm{~mm}$ long. The size and number of heater and temperature sensor elements was chosen to give more resolution in the reactor temperature profile and allow greater control over this profile. An enlargement of the heater and temperature sensor configuration is shown in Fig. 2d.

\section{A)}

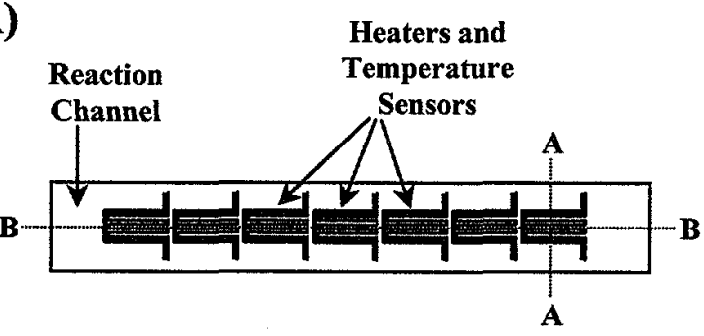

B)

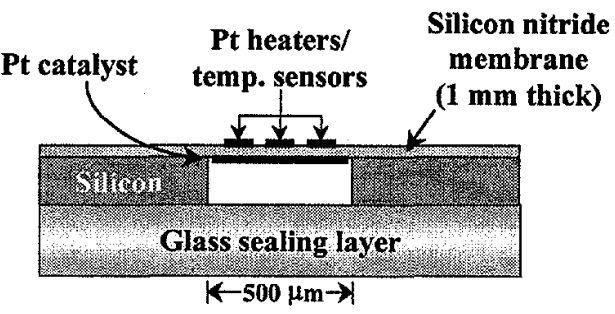

C)

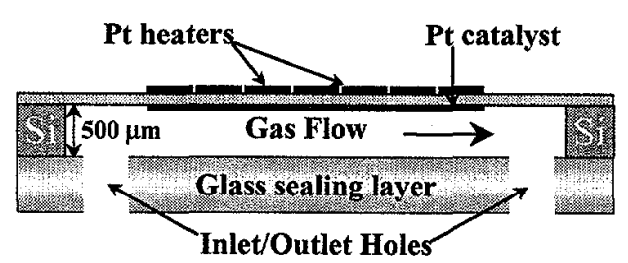

D)

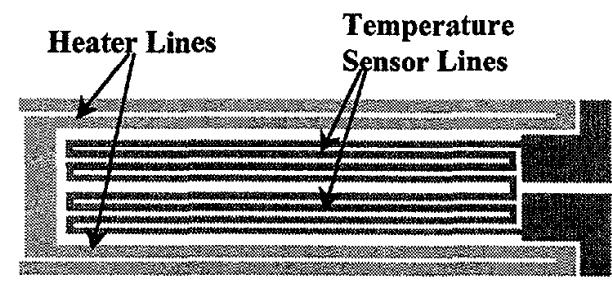

Figure 2. MIT-DuPont scale-up slot microreactor. A) Top-view B) Cross-sectional view AA C) Cross-sectional view $B B \quad D)$ Enlargement of heater and temperature sensor configuration

\section{METHODOLOGY}

The characterization of this type of microreactor has been reported in previous publications[9-12]. The emphasis here is integrating the thin-film reactor design into a hybrid MEMS for chcmical production or catalyst testing. The system design can be divided into three main categories: 1) device packaging, 2) reactor design, and 3) system level integration of microfluidic components and control electronics. The approach taken by the MIT-DuPont program was to first identify methods for packaging and evaluate them. The most suitable method was selected by considering the constraints placed by the reactor design, the chemistries of interest, prototype cost, and overall size. The packaging method, reactor design, and hybridization concept were then based on these initial decisions. The following sections describe each of these components in greater detail.

\section{Device Packaging}

The critical factor in selecting the microreactor packaging was the requirement for fast reactor replacement with the constraint of consistent, robust interconnects. The thin-film reactor design has advantages due to its high level of integration, but its main disadvantage is its fragility. The primary failure mechanism of this microreactor design is membrane rupture, which is generally caused by high temperatures in the reaction zone. However, it can also fail as a result of physical shocks. The MIT-DuPont microreactor also uses a large number of electrical connections. Thus, the first level package screening was to identify a fast, easy method to make electrical contact with the die that was also compact in size. Initial testing of the " $T$ " thin-film microreactor was done using a probe card, but this required precision aligning equipment. This resulted in a test setup with a large footprint due to the probe card size and the micropositioners used. Wire bonding was a sub-optimal choice because of the time required to replace chips (automated wire-bonding was not an option at this stage of development).

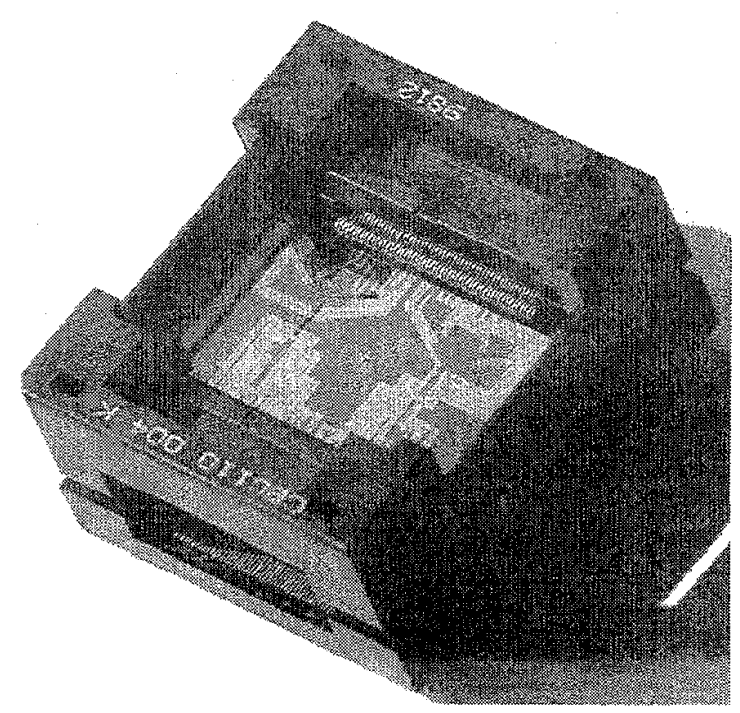

Figure 3. TI DieMate ${ }^{\circledR}$ socket with a mounted 'Y' scale-up microreactor die. 


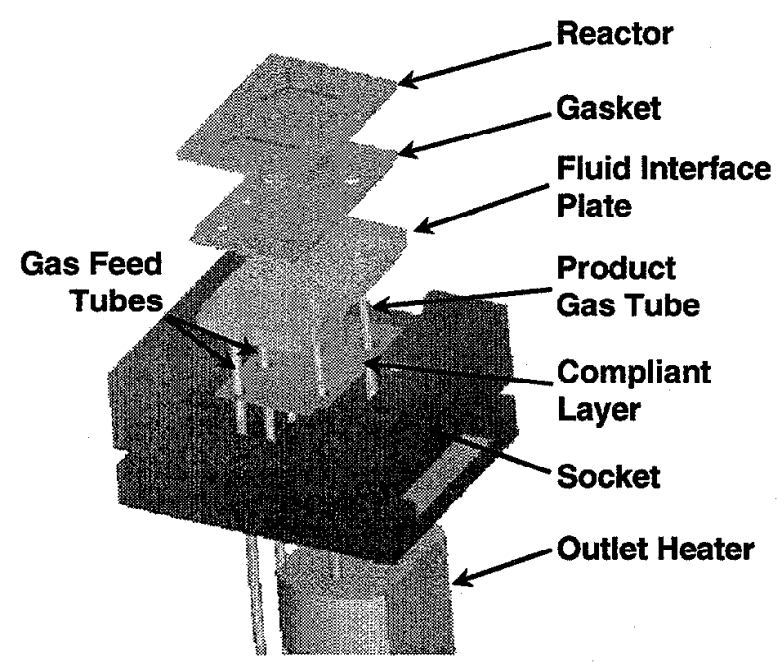

Figure 4. Microreactor fluidic connection assembly.

To solve the microreactor packaging problem, a standard Known Good Die (KGD) socket, manufactured by Texas Instruments, was chosen. This socket, which was originally intended for use in die testing on production lines, was available in a variety of sizes and pin counts. The DieMate ${ }^{(B)}$ socket was designed to be used with a chip mounting assembly for die testing, but this assembly was not needed for our purposes. Instead, the microreactor was designed to fit directly in the socket as shown in Fig. 3. The socket functions with a series of springs that form a pressure contact between the pins and the reactor die. The springs hold the die in place, and by designing the microreactor to fit exactly inside the socket, the system provides a fast, self-aligned method for forming electrical interconnections. The socket also lends itself to easy Printed Circuit (PC) board mounting.

The entire DieMate ${ }^{\circledR}$ microreactor assembly is illustrated in Fig. 4. Since the DicMate ${ }^{8}$ socket was not intended for use with fluidic systems, it was modified to provide a method for interconnecting the gas transfer lines to the microreactor. Referring to Fig. 4, a fluidic connection plate was inserted underneath the reactor die and a compliant layer was placed between these two pieces to form a gas-tight seal using the DieMate ${ }^{(8)}$ springs to provide the sealing force. This connection plate is a piece of flat stainless steel with $1 / 16$ in. o.d. stainless steel tubing welded into it for the reactant and product gas streams.

\section{Reactor Design}

With the DieMate socket chosen as the packaging piece it was necessary to design a reactor to fit into the socket. Since the smallest DieMate ${ }^{\circledR}$ socket available required a die size of $20 \mathrm{~mm}$ by $28 \mathrm{~mm}$, two single channel reactors were placed on a single die. With 110 pins, the socket had more than enough electrical interconnections for the temperature sensors and heaters. Two microreactor designs were developed for this socket. The prototype design was a ' $\mathrm{Y}$ ' shaped reactor that had separate feed inlets for the two reactants. This microreactor can be seen in Fig. 3 mounted in a DieMate ${ }^{\circledR}$ socket. This design was later replaced with a straight channel device for the reasons mentioned previously. Figure 5 shows a picture of the straight channel reactor. Both designs were successful in that all the bond pads aligned as designed with the DieMate ${ }^{(\mathbb{B})}$ pins when inserted into the socket.

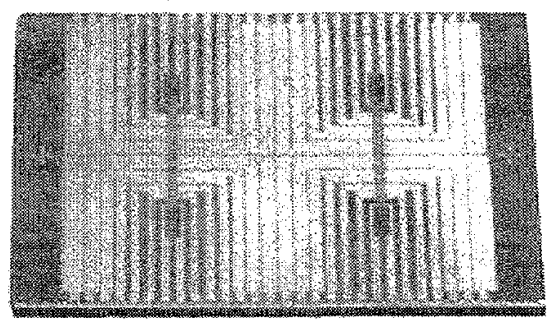

Figure 5. Scale-up slot microreactor.

\section{Hybrid System Design}

The compact reactor packaging allows the integration of the microreactors on PC boards with other MEMS devices to form catalyst test stations or small-scale production units. The hybridization concept is based on mounting devices on standard $6 \mathrm{U}$ CompactPCI boards that will then be inserted into a Kaparel PS6090 chassis to form the final unit as shown in Fig. 6. The individual boards will provide specific functions, such as a reactor card with a reactor and its Mass Flow Controller (MFC). The card will also have some of the electronic circuits needed to run the reactors. Additional circuits will be located on other CompactPCI boards inside the chassis. A CAD drawing of such a card containing a Redwood Microsystems Flow-ister ${ }^{\text {, }}$, a MEMS-based MFC, and a microreactor is shown in Fig. 7. Similar cards will be made for the feed gas lines. The $6 \mathrm{U}$ CompactPCI chassis standard was chosen because of the wide range of backplanes that are available, the larger board sizes possible, and the high number of electrical interconnections available for use. The microreactor test station will use a standard telephony backplane with minor modifications, which can be used directly with the analog signals for device monitoring and control. This CompactPCI chassis will be connected to another CompactPCI chassis containing the control and data acquisition hardware based on National Instruments' PXI/CompactPCI embedded controllers.

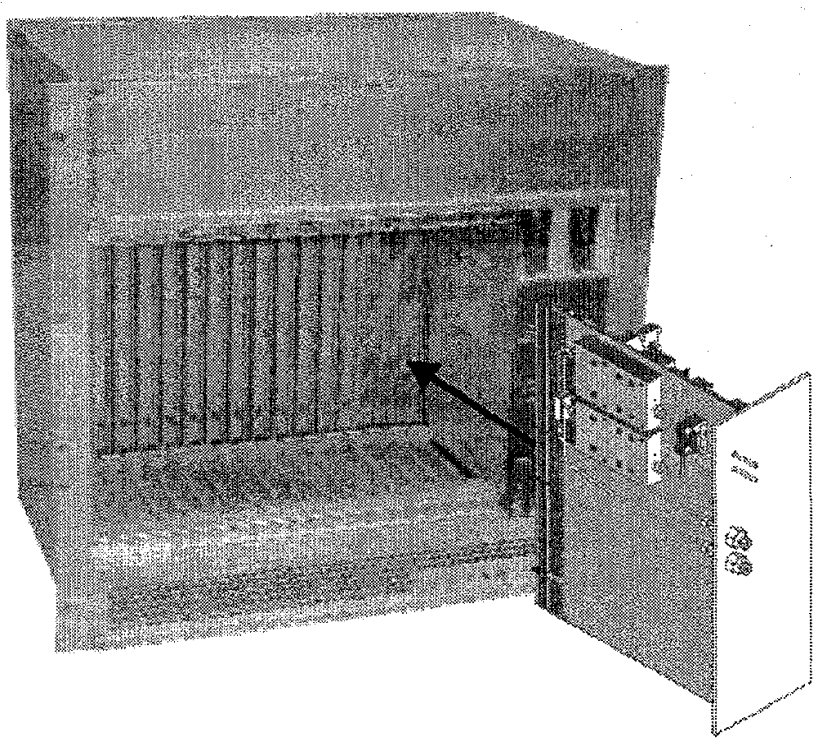

Figure 6. Kaparel PS6090 CompactPCI chassis with a $C A D$ drawing of a fluidic circuit board. 


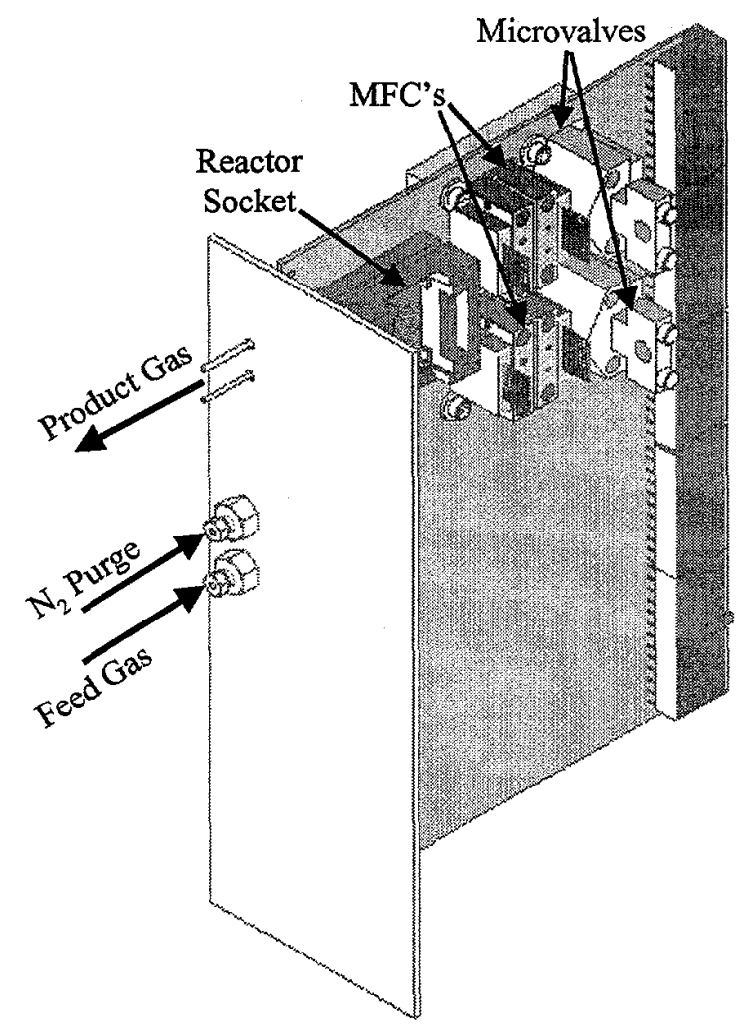

Figure 7. $6 U$ Compact/PCI reactor board with mounted DieMate $^{\circledR}$ socket, Flow-ister ${ }^{\circledR}$ MFC's, and Redwood Microsystems microvalves.

\section{FUTURE WORK}

With the design of the system components completed, current work is focusing on assembling and testing the hybrid microreactor test station. Additional work will focus on the development of a human-machine interface to allow for turnkey style of operation. This will involve building GUI's for operation and developing robust system control algorithms. This is essential not only for ease-of-use, but also for process safety. After this system has been built and tested, a performance comparison between the miniature and conventional systems will be made.

\section{ACKNOWLEDGEMENTS}

The authors thank the DARPA MicroFlumes Program for financial support under contract F30602-97-2-0100. DJQ thanks the National Science Foundation for his graduate fellowship.

\section{REFERENCES}

1. J. J. Lerou, M. P. Harold, J. Ryley, J. Ashmead, T. C. O'Brien, M. Johnson, J. Perrotto, C. T. Blaisdell, T. A. Rensi and J. Nyquist, "Microfabricated minichemical systems: Technical feasibility", Microsystem Technology for Chemical and Biological Microreactors: Papers of the Workshop on Microsystem Technology, Mainz, 20-21 February, 1995, DECHEMA, Frankfurt (1996), pp. 51-69.
2. K. P. Jäckel, "Microtechnology: Application opportunities in the chemical industry", Microsystem Technology for Chemical and Biological Microreactors: Papers of the Workshop on Microsystem Technology, 20-21 February, 1995, DECHEMA, Frankfurt (1996), pp. 29-50.

3. W. Ehrfeld, I. H. Rinard and R. S. Wegeng, Process Miniaturization: 2nd International Conference on Microreaction Technology, AIChE, New Orleans, LA (1998).

4. W. Ehrfeld, Microreaction Technology: Proceedings of the First International Conference on Microreaction Technology, Springer, Berlin (1997).

5. W. Ehrfeld, IMRET 3: Proceedings of the Third International Conference on Microreaction Technology, Springer Verlag, New York (2000).

6. I. Rinard, IMRET 4: 4th International Conference on Microreaction Technology, AIChE, Atlanta (2000).

7. W. Ehrfeld, V. Hessel, H. Möbius, T. Richter and K. Russow, "Potentials and realization of microreactors", Microsystem Technology for Chemical and Biological Microreactors: Papers of the Workshop on Microsystem Technology, Mainz, 20-21 February, 1995, DECHEMA, Frankfurt (1996), pp. 1-28.

8. D. J. Quiram, K. F. Jensen, M. A. Schmidt, P. L. Mills, J. F. Ryley and M. D. Wetzel, "Integrated microchemical systems: opportunities for process design", Foundations of Computer-Aided Process Operations, AIChE, New York (2000),

9. R. Srinivasan, I.-M. Hsing, J. Ryley, M. P. Harold, K. F. Jensen and M. A. Schmidt, "Micromachined chemical reactors for surface catalyzed reactions", Technical Digest of the 1996 Solid-State Sensor and Actuator Workshop, Hilton Head Island, SC, June 3-6, Transducers Research Foundation (1996), pp. 15-18.

10. R. Srinivasan, I.-M. Hsing, P. E. Berger, K. F. Jensen, S. L. Firebaugh, M. A. Schmidt, M. P. Harold, J. J. Lerou and J. F. Ryley, "Micromachined reactors for catalytic partial oxidation reactions", AIChE Journal, 43, 11 (1997), pp. 3059-3069.

11. K. F. Jensen, I.-M. Hsing, R. Srinivasan, M. A. Schmidt, M. P. Harold, J. J. Lerou and J. F. Ryley, "Reaction Engineering for Microreactor Systems", Microreaction Technology: Proceedings of the First International Conference on Microreaction Technology, Springer, Berlin (1997), pp. 2-9.

12. D. J. Quiram, I.-M. Hsing, A. J. Franz, R. Srinivasan, K. F. Jensen and M. A. Schmidt, "Characterization of microchemical systems using simulations", Process Miniaturization: 2nd International Conference on Microreaction Technology, New Orleans, LA, March 9-12, AIChE (1998), pp. 205-210. 